Malathi, P., Subba Rao, K., Seshadri Sastry, P. \& Ganguly, J. (1963). Biochem. 7. 87, 305.

Moore, T. (1953). In Symposium on Nutrition, pp. 28-70. [Herriot, R. M., editor.] Baltimore, Md: Johns Hopkins Press.

Moore, 'T. (1957). Vitamin A, p. 204. Amsterdam: Elsevier.

Murray, T. K. (1962). Proc. Soc. exp. Binl., N.Y., 111, 609.

Nelson, E. C., Dehority, B. A. \& Teague, H. S. (1963). Fed. Proc. 22, 434.

Pasternak, C. A., Humphries, S. K. \& Pirie, A. (1963). Biochem. Y. 86, $3^{82 .}$

Pitt, G. A. J. \& Morton, R. A. (1962). Annu. Rev. Biochem. 31, 491.

Plack, P. A. (1960). Nature, Lond., 186, 234.

Plack, P. A., Kon, S. K. \& Thompson, S. Y. (1958). Biochem. F. 68, 2 P.

Plack, P. A., Kon, S. K. \& Thompson, S. Y. (I959). Biochem. F. 7r, 467.

Pollard, C. J. \& Bieri, J. G. (1959). Biochim. biophys. Acta, 31, 558.

Redfearn, E. R. (1 960). Arch. Biochem. Biophys. 91, 226.

Roberts, K. D., Bandi, L., Calvin, H. I., Drucker, W. D. \& Lieberman, S. (1964). Biochemistry, N.Y., 3,1983 .

Rogers, W. E., Chang, M. L. \& Johnson, B. C. (r963). Fed. Proc. 22, 433.

Sharman, I. M. (I949). Brit. F. Nutr. 3, viii.

Subba Rao, K. \& Ganguly, J. (1964). Biochem. F. 90, 104.

Subba Rao, K., Seshadri Sastry, P. \& Ganguly, J. (1963). Biochem. F. 87, 3 I 2.

Sundaresan, P. R. \& Wolf, G. (1963). Fed. Proc. 22, 293.

Thompson, J. N., Howell, J. McC. \& Pitt, G. A. J. (1964). Proc. roy. Soc. B, 159, 510.

Thompson, J. N., Howell, J. McC., Pitt, G. A. J. \& Houghton, C. I. (1965). Nature, Lond., 205, 1006,

Thompson, J. N. \& Pitt, G. A. J. (1960). Nature, Lond., 188, 672.

Thompson, J. N. \& Pitt, G. A. J. (I961). Biochem. F. 79, 33P.

van Dorp, D. A. \& Arens, J. F. (1946a). Rec. Trav. chim. Pays-Bas, 65, 338.

van Dorp, D. A. \& Arens, J. F. (1946b). Nature, Lond., 158, 60.

Varandani, P. 'T., Wolf, G. \& Johnson, B. C. ( (960). Biochem. biophys. Res. Commun. 3, 97.

Varandani, P. T., Wright, G. J., Wolf, G. \& Johnson, B. C. (I960). Fed. Proc. 20, 242.

Wald, G. (1960). Vitam. $\mathscr{6}$ Horm. 18, 417.

Wald, G. \& Hubbard, R. '(1948-9). Y. gen. Physiol. 32, 367.

Weissmann, G., Bell, E. \& Thomas, L. (1963). Amer. F. Path. 42, 57 I.

Weitzel, G. \& Schnapka, G. (1964). Schweiz. med. Wschr. 94, 218.

Winterstein, A. \& Hegedüs, B. (1960). Hoppe-Seyl. Z. 321, 97.

Wolf, G., Bergan, J. G. \& Sundaresan, P. R. (1963). Biochim. biophys. Acta, 69, 524.

Wolf, G. \& Johnson, B. C. (1960a). Vitam. E Horm. 18, 403.

Wolf, G. \& Johnson, B. C. (1960b). Vitam. छ Horm. 18, 439.

Wolf, G., Kahn, S. G. \& Johnson, B. C. (1957). F. Amer. chem. Soc. 79, 1208.

Wolf, G., Varandani, P. T. \& Johnson, B. C. (1961). Biochim. biophys. Acta, 46, 59.

Wright, G. J. (I96I). Amer. F. clin. Nutr. 9, no. 4, part 2, p.26.

Wu Chang, M. L. \& Willis, E. (I963). Fed. Proc. 22, 434.

Yagishita, K., Sundaresan, P. R. \& Wolf, G. (1964). Nature, Lond., 203, 410.

Zachman, R. D. \& Olson, J. A. (1964). Nature, Lond., $201,1222$.

Zachman, R. D. \& Olson, J. A. (1965). F. Lipid Res. 6, 27.

Zile, M. \& DeLuca, H. F. (I 964). Fed. Proc. 23, 294.

\title{
The effect of vitamin $A$ on the breakdown and synthesis of intercellular material in skeletal tissue in organ culture
}

\author{
By Honor B. Fell (Royal Society Researci Professor), Strangeways Research \\ Laboratory, Cambridge
}

In a previous talk to the Society in 1959, I gave an account of our studies of the direct action of vitamin A on tissue structure (Fell, 1960); the present paper deals with the sequel to this early work.

My interest in the action of vitamin A was aroused by the late Sir Edward Mellanby. It is known that, when animals are fed on a diet containing excess of vitamin $A$, their bones undergo severe resorption often accompanied by spontaneous 
fractures. How did vitamin A produce this effect? At the Strangeways we had developed a technique for growing entire bones from chick and mouse embryos, in small dishes of nutritive medium (Fell \& Robison, 1929). Mellanby thought that this method of cultivating whole bones in vitro might shed light on the mechanism through which the vitamin acted on the tissue. The object of these initial experiments was merely to discover whether vitamin A had a direct action on skeletal tissue, as this was quite uncertain at that period and many people thought that the resorption of bone and cartilage in hypervitaminosis $\mathrm{A}$ was mediated through the parathyroid or some other endocrine system.

Obviously, if vitamin A produced an effect on bone and cartilage grown as an organ culture in vitro, this could only mean that the vitamin has a direct action on the tissue, because all systemic reactions are, of course, eliminated in a culture. We were delighted to find that the addition of vitamin $A$ to the culture medium had a very drastic effect on the explants, and caused a rapid dissolution of the intercellular material (Fell \& Mellanby, 1952). These changes in bone and cartilage were not necrotic, and the healthier and more active the cells, the more rapid was the breakdown of intercellular substance. Later work (Fell, Dingle \& Webb, I962) showed that this action of the vitamin had a high degree of molecular specificity.

The main object of our recent work has been to discover the cellular mechanism of this dissolution of intercellular material in response to excess of vitamin A. My biochemical colleagues, J. T. Dingle and J. A. Lucy, and I decided to investigate some of the biochemical effects of the vitamin on the cartilaginous limb-bone rudiments from 7-day embryos (Dingle, Lucy \& Fell, 1961). The oxygen consumption of the vitamin A-treated rudiments was depressed as compared with that of their controls, the wet and dry weights and hexosamine content of the vitamin A-treated explants were half those of the paired controls, but their DNA content was only $20 \%$ less.

For a long time $I$ had noticed that any tissue grown on a semi-solid medium composed of blood plasma and embryo extract, and containing added vitamin $A$, liquefied the clot more than controls in normal medium. This led me to suspect that the vitamin was increasing the proteolytic activity of the explants; in particular I wondered whether the acid proteases known as cathepsins were involved. The idea that a protease might be responsible for the dissolution of cartilage matrix in response to vitamin A received some encouragement from 'Thomas's (I 956) observation that, when the vegetable protease, papain was injected into rabbits, it caused a rapid loss of cartilage matrix in the living animal. In joint work (Fell \& Thomas, 1960), Thomas and I found that papain protease added to the culture medium of cartilaginous explants produced an effect on the matrix that closely resembled that caused by excess of vitamin $A$.

Dingle and I examined the effect of vitamin A on the proteolytic activity of cartilaginous limb-bone rudiments from 7 -day chick embryos, grown in organ culture (Fell \& Dingle, 1963). We were able to show that in $24 \mathrm{~h}$ the cartilage grown in the presence of vitamin A released into the culture medium up to seven times as much acid protease as the paired controls in normal medium. But when we examined the cartilage itself, we found that it still retained at least as much proteolytic activity as 
the control, and sometimes more. So we concluded from this that the increased release of enzyme in response to vitamin A was compensated by an increased synthesis.

In other experiments (Dingle et al. 1961; Fell \& Dingle, 1963) we found that acid protease acts on the matrix by breaking down the protein moiety of the proteinmucopolysaccharide complex, and in this way liberates polymeric chondroitin sulphate from the tissue. We also found (Fell \& Dingle, 1963) that, although the pH optimum of the enzyme is around $5^{\circ}$, it nevertheless actively degrades cartilage matrix at a neutral $\mathrm{pH}$, though more slowly.

Just recently we have obtained further evidence that the breakdown of the cartilage is due to the acid protease. Ali (1964) has shown that $\epsilon$-aminocaproic acid, which inhibits the enzyme plasmin, also inhibits the acid protease of cartilage. Stimulated by this work, we added this inhibitor to the culture medium along with the vitamin $\mathrm{A}$, and found that the protease inhibitor largely prevented the action of the vitamin on the cartilage matrix.

de Duve and his colleagues (de Duve, Pressman, Gianetto, Wattiaux \& Appelmans, 1955) have shown that a similar acid protease is localized in a bound form, in certain cytoplasmic granules which they have termed 'lysosomes'. These granules, which were discovered in tissue fractionation studies on the rat liver, contain about a dozen acid hydrolases (de Duve, ${ }_{1963}$ ) which can be released from the particles in vitro by hypotonicity, detergents and other destructive agents.

Dingle wondered whether the increased proteolytic activity of cartilage grown in the presence of excess of vitamin A might be due to an effect on the lysosomes of the chondrocytes. It seemed possible that the vitamin might alter the permeability of the lipoprotein membranes of these organelles, and thus release the cathepsin, along with other enzymes. He therefore isolated the lysosomal granule fraction from rat liver (Dingle, I96r), embryonic chick cartilage (Fell \& Dingle, 1963) and other tissues and treated it in vitro with vitamin $A$. The vitamin rapidly released the hydrolytic enzymes that the lysosomes contained; this observation of Dingle's gave us the key to the effect of hypervitaminosis A on skeletal tissue. The effect was dose-dependent and temperature-dependent (Dingle 196I) and had a high degree of molecular specificity (Fell et al. 1962), which in general corresponded to that for preventing vitamin A deficiency in animals.

From all these results, we concluded that vitamin $A$ activates the lysosomes of the chondrocytes and thus releases the lysosomal hydrolases including the cathepsin; this protease then digests the protein moiety of the mucopolysaccharide complex of the matrix which consequently disintegrates; release of the enzyme is compensated by an increase in its synthesis.

It is probable that a lysosomal mechanism is also responsible for the breakdown of bone matrix, though at present there is no direct proof of this. It is known, however, that foetal bone contains lysosomal enzymes (Vaes, 1964), and that these can be released from particulate preparations in vitro by the addition of vitamin $A$ (Fell \& Dingle, quoted by Fell, 1964); cytochemical studies by several authors have shown that osteoclasts are filled with lysosomal granules. Moreover, the resorption 
of bone grown in the presence of excess of vitamin $A$ can be much reduced by simultaneous addition to the medium of the cathepsin inhibitor, $\epsilon$-aminocaproic acid (Fell \& Dingle, unpublished).

Change in lysosomal stability in response to excess of vitamin $A$ is not confined to in vitro systems, but also takes place in the intact animal (Dingle, Sharman $\&$ Moore, 1963; Weissmann, Uhr \& Thomas, 1963).

The effect of vitamin $\mathrm{A}$ on bone and cartilage in culture can be greatly retarded by adding hydrocortisone to the medium (Fell \& Thomas, 1961); this hormone has been shown to stabilize lysosomal and other membrane systems (de Duve, Wattiaux \& Wibo, I962; Weissmann \& Dingle, I961; Weissmann \& Thomas, I963).

Recently we have investigated the effect of vitamin A on the synthesis of the components of cartilage matrix. The vitamin causes the breakdown of the fully formed matrix, but it was not known whether the chondrocytes continue to synthesize the components of the matrix, but merely release the products into the culture medium because the increased proteolytic activity prevents them from being built into intercellular material.

To answer this question, Dingle, Lucy and I (unpublished) grew 7-day chick limb-bone rudiments in a chemically defined fluid medium. Every 2 days the old medium was sucked off with a pipette and collected, and at the end of the culture period of 8 days the bone explants also were harvested. My colleagues then estimated the amount of hexosamine and hydroxyproline in both the medium and the tissue, as these substances are two of the main constituents of cartilage matrix. We found that the vitamin A-treated explants synthesize much more hydroxyproline and hexosamine than would appear from examination of the cartilage alone, but they liberate relatively more into the medium than the controls do. If the effect of the vitamin is not too severe, the total amount of hydroxyproline and hexosamine synthesized may be almost as great as in the controls, but usually it is rather less.

At present we have no idea whether the well-known effects of the vitamin on epithelia are mediated through the same cytological mechanism as its action on bone and cartilage. On the whole, we incline to the view that, in epithelia, changes in the endoplasmic reticulum and the ribosomes may be primarily concerned, but this is a mere guess, and in the end we may find that the lysosomes are implicated here also.

The lysosomal membranes are not the only membrane systems to be affected by vitamin A, as Dingle \& Lucy (1965) will show in the next paper.

\section{REFERENCES}

Ali, S. Y. (1964). Biochem. F. 93,611.

de Duve, C. (1963). Lysosomes. Ciba Found. Symp. p. t.

de Duve, C., Pressman, B. C., Gianetto, R., Wattiaux, R. \& Appelmans, F. (1955). Biochem. F. 60, 604.

de Duve, C., Wattiaux, R. \& Wibo, M. (1962). Biochem. Pharmac. 8, 30.

Dingle, J. T. (1961). Biochem. . 79, 509 .

Dingle, J. T. \& Lucy, J. A. (1965). Proc. Nutr. Soc. 24, 170.

Dingle, J. T., Lucy, J. A. \& Fell, H. B. (1961). Biochem. Ұ. 79, 497.

Dingle, J. T., Sharman, I. M. \& Moore, T. (1963). Proc. Nutr. Soc. 22, x.

Fell, H. B. (1960). Proc. Nutr. Soc. I9, 50.

Fell, H. B. (1964). In Bone and Tooth. Proceedings of the First European Symposium, p. 3 II.

[H. J. J. Blackwood, editor,] London: Pergamon Press. 
Fell, H. B. \& Dingle, J. T. (1963). Biochem. 7. 87, 403.

Fell, H. B., Dingle, J. T. \& Webb, M. (1962). Biochem. F. 83, 63.

Fell, H. B. \& Mellanby, E. (I952). F. Physiol. 116, 320.

Fell, H. B. \& Robison, R. (1929). Biochem. F. 23, 767.

Fell, H. B. \& Thomas, L. (1960). F. exp. Med. 111, 719.

Fell, H. B. \& Thomas, L. (1961). F. exp. Med. 114, 343 .

Thomas, L. (1956). F. exp. Med. 104, 245.

Vaes, G. (1964). Abstr. Fed. Europ. biochem. Socs, 1, 83 .

Weissmann, G. \& Dingle, J. (196r). Exp. Cell Res. 25, 207.

Weissmann, G. \& Thomas, L. (1 963$)$. F. clin. Invest. 42, 661.

Weissmann, G., Uhr, J. W. \& Thomas, L. (г963). Proc. Soc. exp. Biol., N.Y., r12, 284.

\section{Membrane phenomenons in relation to vitamin $\mathbf{A}$}

\section{By J. T. Dingle and J. A. Lucy, Strangeways Research Laboratory, Cambridge}

One way of studying the organization and properties of the lipid components of membranes is to investigate the effect on membranes of various agents known to interact with lipids. Vitamin A has recently been found to have this property; studies made at the Strangeways Laboratory on the interactions of the vitamin with membranes have yielded information that may be relevant both to the structure and function of biological membranes and to the mechanisms of action of vitamin $\mathrm{A}$.

Excess of the vitamin affects the membranes of a number of cells and intracellular organelles (reviewed by Fell, 1965a, and Lucy \& Dingle, I 964a). Examples of such changes have been seen in electron micrographs of fibroblasts grown in the presence of retinol (Daniel, Dingle, Glauert \& Lucy, unpublished observations). A disappearance of the granular endoplasmic reticulum of these cells was observed, which was accompanied by a marked increase in the number of free ribosomes. The appearance of small invaginations in the plasma membrane and the formation of many myelinated bodies were noted. Mitochondrial swelling was observed after $6 \mathrm{~h}$ growth in the presence of the vitamin, at which time a depression of respiratory activity occurred; these findings may be related to the swelling seen in isolated mitochondria after treatment with retinol (Lucy, Luscombe \& Dingle, 1963).

Lysosomes were present in both the control and experimental cells, but there was an increase in the number of cytolysomes in retinol-treated fibroblasts. Cytolysomes are believed to be lysosomes that are particularly concerned in the degradation of damaged cellular organelles (Novikoff \& Essner, 1962). This change in lysosomal type may be correlated with the decreased stability of lysosomes in retinol-treated tissues in culture (Fell \& Dingle, ${ }^{9} 9_{3}$ ) and in hypervitaminotic animals (Dingle, Sharman \& Moore, 1963). As stated in Dame Honor Fell's $\left(19^{6} 5^{b}\right)$ paper, the release of lysosomal enzymes by vitamin A causes many of the changes observed in cartilage and probably those produced in bone also (Fell \& Mellanby, 1952).

Information on the mode of action of the vitamin on lipoprotein membranes has come from studies on both biological and artificial membranes. Studies made with the electron microscope on rabbit erythrocytes treated with excess of vitamin $A$ in vitro have shown that retinol causes indentations of the membrane and the production of vacuoles by a process resembling micropinocytosis (Glauert, Daniel, Lucy 